\title{
Assessment of Agro-Chemicals Utilization by Small-Scale Farmers in Guyuk, Adamawa State, Nigeria
}

\author{
Jamala, G. $\mathrm{Y}^{1^{*}}$, Ari, B. $\mathrm{M}^{2}$, Tsunda, B. $\mathrm{M}^{1}$ and Waindu, $\mathrm{C}^{1}$ \\ ${ }^{I}$ College of Agriculture, Ganye, Adamawa State, Nigeria \\ ${ }^{2}$ Adamawa State University, Mubi, Nigeria
}

\begin{abstract}
The study assessed the utilization of Agro-chemicals among small scale farmers in Guyuk Local Government Area of Adamawa State. Ninety five (95) respondents were selected using multi-stage, purposive and random sampling techniques. The data collected were analyzed using descriptive and inferential statistics. The result shows the distribution of respondents according to their age, $12.63 \%$ are less than 20 years, $13.68 \%$ are within the age of 21 to 30 years, $14.738 \% 31$ to 40 , years, $16.84 \% 41$ to 50 years, $21.05 \%$ ranging between 51-60 years while $21.0 \%$ of them are 60 year and above. It shows that the majority of the farmers fall within the age of 51 to 60 years. The gender distribution of the farmers shows that $68.42 \%$ of the respondents were male while $31.78 \%$ are female. $48.4 \%$ of the respondents have 6-10 members of family in a household. Based on educational level of the respondents, majority of the respondents (36.84\%) had Tertiary education while $31.58 \%$ had secondary school education. Majority of the respondents (35.8\%) had farming experience of over 30 years. According to the distribution of farm size, majority of the respondent $(52.6 \%)$ had less than 1 hectare $(<1 \mathrm{ha})$, $27.4 \%$ had between 1 and 5 hectares and 20.0\% between 6 and 10 hectares. Based on sources of agrochemicals, the result revealed that the majority of the respondents (65.3\%) got their agro-chemicals in the open market while $18.9 \%$ through extension workers and $15.8 \%$ through non-governmental organization. The distribution of respondents according to the most utilized agro-chemicals. Majority (42.1\%) maintained that they make use of fertilizer and $36.8 \%$ uses pesticides than other forms of agro-chemicals. Distribution of respondents according to whether agro-chemicals are harmful or not, majority of the respondents $(83.2 \%)$ responded that agro chemicals are harmful and $16.8 \%$ pointed out that agro-chemicals are not harmful. Majority $51.58 \%$ of the respondents maintained that agro-chemicals did not affect their farm income, $48.42 \%$ pointed out that Agro-chemicals had positive impact on their farm income. Based on the constraints to adoption of agro-chemicals, most of the respondents pointed out that the major constraint to adoption of agro-chemicals is inadequate fund. Majority of the farmers are poor. On the other hand, some of the farmers pointed out that it is difficult to apply agro-chemicals and they do not have the skill and equipment to use on their farms. Agrochemicals application requires safety measures like hand globes, and protective clothing to avoid contact with the body, this discourages farmers from applying agro-chemical on their farms. Most agro-chemicals possess offensive odour which may affect adoption, by and large some farmers maintained that they are allergic and hence do not like the odour and cannot use it on their farms. $18.95 \%$ of the respondents indicated that they use to get between $\mathrm{N} 200,000-\mathrm{N} 250,000$ and above due to utilization of agro-chemicals on their farms. The result of regression shows a coefficient of multiple determinations $\left(R^{2}\right)$ value of 0.036 which indicates that $3.6 \%$ of the variation in output was accounted for by the variation in explanatory variable used in the model. The remaining $96.4 \%$ may be attributed to error. The coefficient of herbicide $\left(X_{I}\right)$ was positive and significant $(P<0.01)$. The positive coefficient suggests that a percentage increase in the variable would result to increased output level. The result of $X^{2}$ at $10 \mathrm{DF}, 6 \mathrm{DF}$ and $12 \mathrm{DF}(P<0.05)$ level of significance $=1.812,1.943$ and 1.782. The calculated $X^{2}$ values of 16.094, 22.479 and 22.288 are greater than critical (Table) values, this revealed that there was significance association between agro-chemicals utilization and some selected socio-economic variables: Age, Level of education and income while the $X^{2}$ at 2 DF at 0.05 level of significance $=1.697$. The calculated value (0.122) is less than the critical (Table) value, so the result indicates that there was no significant association between Agro-chemicals utilization and Gender.
\end{abstract}

Keywords: Farmers, Utilization, Agro-chemicals, Assessment, Small scale, Production

\section{Introduction}

Agrochemicals refers to the broad range of pesticides including insecticides, fertilizers, hormones, herbicides, fungicides, and other growth chemicals and concentrated stores of raw animal manure (cow dung and poultry droppings). Globally, agro-chemicals (agrichemicals) are used for improving soil fertility and productivity. These methods of farming have been used in agriculture especially cropping system. The old civilization used organic manure (cow dung and poultry dropping) as a means of providing nutrients to the crops for a long period with consistent yield (Albert, 1989). According to Alex (2007), the use of agrochemicals is 
dangerous to the health of both the soil and humans. Agrochemicals on other hand, is expensive and unaffordable by many small-scale farmers.

Many agrochemicals are toxic and agrochemicals in bulk storage may pose a significant environmental and/ or health risks particularly in the event of accidental spills (Andrew, 2007). In many countries the use of agrochemicals is highly regulated. Government issues permits for purchase and use of approved agrochemicals may be required. Significant penalties can result from misused including improper storage resulting in the spillage. On-farm, proper storage facilities and labeling, emergency clean up equipment and procedure for handling, application and disposal are often subject to mandatory standards and regulation. Usually the regulations are carried out through the registration process (Andrew, 2008).

The use of these agro-chemicals though on one side accounts for increased yield, on the other hand the products are of less natural content and contain some heavy chemicals. These agro-chemicals to some extent proved harmful not only for humans but also pose a great danger to the environment. The continuous usage of these chemicals for about 15 years was reported to turned cultivated land into barren land (Andrew, 2007).

Fleisher, (2006) reported that the use of synthetic fertilizers and chemical pesticides in the developing countries has grown substantially during the past four decades. Government promoted the use of agro-chemicals in other to achieve national food security and improve the production of export crops.

A range of policy intervention is necessary to create an enabling environment for the utilization of agro-chemical practices by farmers in the rural areas. Regulating policy play an important role in restricting access to most toxic and damaging chemicals and regulating its use. Farmer's access to information about sustainable agricultural technologies and practices needs to be improved on other hand, agricultural extension services need to be strengthened. Economic incentives can play a major role in stimulating environmental friendly technologies.

According to Maisamari (2001), a community based study in ten villages in Githunguri, Kiambu district was conducted to establish the extent of use of agro-chemicals and to assess the attitudes, behavior and general awareness of the people of the health hazards posed by improper handling of agro-chemicals. The use of agro-chemicals in general, was found to be extensive. Furthermore, Kenya's economy is dependent on agriculture and the agricultural sectors uses enormous quantities, although, most often they neither follow instruction nor understand the potential hazards of careless handling of these agro-chemicals. In Europe, prior to the late $19^{\text {th }}$ centuries, cottage industries, mostly small and medium scale businesses control the economy, the industrial revolution changed the status-quo and undermine the mass production model which triggered an unexpected reappraisal of role of small and medium sized enterprises. There is no doubt that yet findings by economists globally over the years show that small firms and entrepreneurship play more important role in economic growth and development (NEH, 2003).

According to SMSEFN (2003), the benefits of small and medium scale enterprises to any economy are easily noticeable.

In addition after using chemical fertilizers for a few seasons there seems to be significant crop destruction from insect inversion. The use of dichlorodiphenyltrichloroethane (DDT) was sometimes thought to be safe, latter it was discovered that it contain powerful cancer causing substances. It was also discovered that the insect that were not killed by the DDT, produced offspring that were immune to it (Peres et al., 2006).

\section{Sources of Agro-chemicals}

The distribution of agro-chemicals to end-users is not often address by health professional. Researchers frequently carry out survey base on official record of importation and sales collated by the government and its affiliated agencies. However as it is shown by professor Mbiapo, official data often do not reflect the real situation. Rather, access to pesticide follows the vagaries of the black market, smuggle goods, and alternative marketing.

Moreover, several industrialized countries have recently undertaking to review their pesticide registration procedures. Such experiences could form the bases of either similar reviews or the actual establishment of up-to-date regulation in developing countries. However, even in countries where the regulation is non-existent or it enforcement too weak to make a difference, it is necessary to protect users ( $\mathrm{FAO} / \mathrm{WHO}$, 1988).

\section{Effects of Agro-chemicals}

Fleisher (2006) reported that although, the excessive use of chemical fertilizer in developing countries often receives less attention than the use of pesticides, economic and ecological impact can be dramatic. Bangladesh faces severe loss of topsoil fertility from over use of chemical fertilizer and pesticides. Although, pesticides are use in agricultural and public health programs, the method differs and the parameter for measuring their efficacy or cost effectiveness varies greatly. However, the development of pest resistance to pesticide and their effects on non- target organism including human, have a similar impact and are of equal significant. Moreover the use of pesticide in one sector affects the other. It has been summarized that large-scale spraying of 
dichlorodiphenyltrichloroethane (DDT) on cotton in Central America was responsible for the development of resistance of the pesticide in Anopheles spp. which were malaria vectors (Chapin and Wassertrom, 1981).

According to Andrew (2008), the use of certain agro-chemical has also been associated with some important ecological damages. Excessive use of fertilizers for example, can lead to the contamination of ground water with nitrate, rendering it unfit for consumption by humans or livestock. Water containing large concentration of nitrate can poison animal by immobilizing some of the haemoglobin in blood, reducing the ability to transport oxygen. In addition the run-off of agricultural fertilizer into streams, lakes and other surface water can cause an increase productivity of those aquatic ecosystems, a problem known as eutrophication.

As observed over the years farmers are faced with low yield due to poor performance of soil and random utilization of agro-chemicals (Seattle, 2008). It is important to assess the sources of agro-chemicals used, the perceived effects on production and the level of utilization in Guyuk.

\section{Materials and Methods}

\section{The Study Area}

The study was conducted in Guyuk local government area of Adamawa State, Nigeria. The area lies between latitude $9^{\circ} 30$ and $10^{\circ}$ North and longitude $11^{\circ} 30$ and $12^{\circ} 00$ East. The area has an average temperature of $26.1^{\circ} \mathrm{C}$ (December to January) and $33^{\circ} \mathrm{C}$ (April to May) (Adebayo, 1999). The area received an average rainfall of 700-800mm per annum (Adebayo and Tukur, 1999).

Guyuk local government area has the total land mass of about 24215 square kilometer, with population of 176,505 (NPC, 2006). The area is located within the Guinea Savannah Zone of the Nigeria's vegetation Zones (Adebayo 1999). The major economic activity in the area is agriculture, food crops grown in the area includes Maize, sorghum, cowpea, Cotton and Potatoes. The famers are also engaged in collection and processing of non-timber forest such as Shea nuts. Major livestock reared in the zones are cattle, Pigs, Sheep and Goats (AD ADP Guyuk, 2011).

\section{Sampling Procedure and Sampling Size}

The respondents (farmers) interviewed were selected using Multi-stage, purposive and random sampling techniques in ten wards of the study area. First five villages were purposively selected based on their relative utilization of agro-chemicals. They are: Guyuk, Lokoro, Banjiram, Gugu and Jiu. From each selected village, 22 farmers were randomly selected for frequent utilization of agro-chemicals.

A sample of 110 farmers formed the sample size. At the end of data collection only 95 questionnaires were correctly filled and returned. The remaining 15 were rejected owing to inconsistencies in their responses.

\section{Analytical Tools}

Data obtained were analyzed using descriptive statistics that include the use of frequency distributions and percentages. Chi-square $\left(\chi^{2}\right)$ was used to test for the presence of associations in the variables obtained.

$$
X^{2}=\frac{\sum(f o-f e)}{f e}
$$

Where $\mathrm{X}^{2}=$ Chi-square

$$
\text { Fo }=\text { observed frequency }
$$

$$
\mathrm{Fe}=\text { expected frequency }
$$

Simple regression formula

Linear Equation

$$
\mathrm{Y}=\mathrm{a}+\mathrm{bx}_{1}
$$

Where:

$\mathrm{Y}=$ Income

$\mathrm{a}=$ constant

$\mathrm{b}=$ coefficient

$\mathrm{X}_{1}=$ herbicide

\section{Results and Discussion}

\section{Socio-economic characteristics of farmers in the study area}

The socio-economic characteristics of the respondents include age, gender, level of education, marital status, farm size, family size, house hold size and farming experience.

The study was a representative of both male and females. The result in Table 1 summarized the age range, gender, marital status, household size, level of education, farming experience and farm size of the respondents in the study area. 
The result shows the distribution of respondents according to their age, $12.63 \%$ are less than 20 years, $13.68 \%$ are within the age of 21 to 30 years, $14.738 \% 31$ to 40 , years, $16.84 \% 41$ to 50 years, $21.05 \%$ ranging between $51-60$ years while $21.0 \%$ of them are 60 year and above. It shows that the majority of the farmers fall within the age of 51 to 60 years. This indicates that farmers within this age group are more dynamic to innovation and adoption rate. The gender distribution of the farmers shows that $68.42 \%$ of the respondents were male while $31.78 \%$ are female. This variation could be attributed to the fact that most farms in the study area are owned by men even though women also participate actively in farming activities. The assessment of this study is in line with the findings of Okonjo (1991) who posited that $70 \%$ of women in rural areas were also engaged in food production. The result could also be attributed to the fact that women are controlled by their husband or their fathers in the study area and they usually refer researchers to give information concerning their farms or farming activities.

The marital status of the respondents shows that $68.4 \%$ were married, it implies that most of the Farmers in the study area have access to family labour who participate actively in farming activities.

Table 1 shows that $(48.4 \%)$ of the respondents has 6-10 members of family in a household. This implies that most of the farmers in the study area have a large family size. Thus the large family size will provide more labour to the household. This finding is in line with the findings of Williams (2007) who posited that large household will provide labour requirement for the family. Family size is proxy for labour.

Based on educational level of the respondents, majority of the respondents (36.84\%) had Tertiary education while $31.58 \%$ had secondary school education. This result is in line with the findings of Mohammed et al. (2005) that educational background of farmer's accounts for their managerial ability and makes them to accept agro-chemicals as increasing soil fertility and production. Oladele (2005) found out that the exposure of farmers to education will increase the farmer's ability to obtain and use information relevant to adoption of agro-chemical.

Majority of the respondents (35.8\%) had farming experience of over 30 years. Farming experience of farmers is reported to increase their tendency of adopting improved techniques such as the use of agrochemicals. Hailu (2008) reported that more experienced farmers are knowledgeable and more likely to adopt new techniques.

The result of this study Table 1 reveals that the majority of the respondent (52.6\%) had farm size of less than 1 hectare ( $<1$ ha), 27.4\% had farm size of between 1 and 5 hectares and $20.0 \%$ had a farm size of between 6 and 10 hectares. The result of this study concurs with the findings of Bzugu et al. (2009) who reported that majority of farmers in Adamawa State cultivate less than one hectare of land. From the result of this study, it can be said that most farmers in the study area are small scale farmers (peasant). Oladele (2005) noted that farm size is an indicator of wealth and perhaps a proxy for social status and influence within community that depends on agricultural production as a major occupation for source of income and is expected to be positively associated with the decision to adopt agro-chemicals as a source of increasing productivity. Olusi (2007) reported that farm size has a close positive association with the ability to obtain credit as a major determinant of adopting farm practice.

Table 1: Distribution of Respondents According to Socio-Economic Characteristics

\begin{tabular}{lll}
\hline Respondents & Frequency & Percentage \\
\hline Age & & \\
$<20$ & 12 & 12.63 \\
$21-30$ & 13 & 13.68 \\
$31-40$ & 14 & 14.73 \\
$41-50$ & 16 & 16.84 \\
$51-60$ & 20 & 21.05 \\
Above 60 & 20 & 21.05 \\
Total & $\mathbf{9 5}$ & $\mathbf{1 0 0 . 0 0}$ \\
Gender & & \\
Male & 65 & 68.42 \\
Female & 30 & 31.78 \\
Total & $\mathbf{9 5}$ & $\mathbf{1 0 0 . 0 0}$ \\
Marital Status & & \\
Married & 65 & 68.40 \\
Single & 15 & 15.90 \\
Divorced & 10 & 10.50 \\
Widow & 5 & 5.20 \\
Total & $\mathbf{9 5}$ & $\mathbf{1 0 0 . 0 0}$ \\
House Hold Size & & \\
$1-5$ & 28 & 29.50 \\
6-10 & 46 & 48.40 \\
$11-15$ & 14 & 14.70 \\
16-20 & 5 & 5.30 \\
Above 20 & 2 & 2.10 \\
\hline
\end{tabular}


Assessment Of Agro-Chemicals Utilization By Small-Scale Farmers In Guyuk, Adamawa State,

\begin{tabular}{lll}
\hline Total \\
Level of Education & $\mathbf{9 5}$ & $\mathbf{1 0 0 . 0 0}$ \\
Adult literacy & 7 & 7.37 \\
Primary & 23 & 24.21 \\
Secondary & 30 & 31.58 \\
Tertiary & 35 & 36.84 \\
Total & $\mathbf{9 5}$ & $\mathbf{1 0 0 . 0 0}$ \\
Farming Experience & & \\
$<10$ & 2 & 2.10 \\
$11-20$ & 5 & 5.30 \\
$21-30$ & 10 & 10.50 \\
$31-40$ & 20 & 21.00 \\
$41-50$ & 24 & 25.30 \\
Above 50 & 34 & 35.80 \\
Total & $\mathbf{9 5}$ & $\mathbf{1 0 0 . 0 0}$ \\
Farm Size & & \\
$<1$ & 50 & 52.60 \\
$1-5$ & 26 & 27.40 \\
6-10 & 19 & 20.00 \\
Total & $\mathbf{9 5}$ & $\mathbf{1 0 0 . 0 0}$ \\
\hline
\end{tabular}

Source: Field Survey, 2012.

Source of Information

The result of this study in Table 2 reveals that the majority of the respondents (65.3\%) got their agro-chemicals in the open market while $18.9 \%$ through extension workers and $15.8 \%$ through non-governmental organization. This implies that most farmers obtained agro-chemicals in the open market.

Table 2: Distribution of Respondents According to Source of Information

\begin{tabular}{lll}
\hline Source & Frequency & Percentage \\
\hline Extension & 18 & 18.90 \\
Market & 65 & 65.30 \\
Non-governmental (NGOs) & 15 & 15.80 \\
Total & $\mathbf{9 5}$ & $\mathbf{1 0 0 . 0 0}$ \\
\hline
\end{tabular}

Source: Field Survey, 2012.

\section{Most Utilized Agro-chemicals}

Table 3 shows the distribution of respondents according to the most utilized agro-chemicals. Majority $(42.1 \%)$ maintained that they make use of fertilizer and $36.8 \%$ uses pesticides than other forms of agrochemicals. This agrees with the findings of News (1967) who posited that application of fertilizer and pesticides increased crop yield. The result also shows that when fertilizer and pesticides are combined give more yield.

Table 3: The Distribution of Respondents According to the Most Utilized Agro-Chemicals

\begin{tabular}{lll}
\hline Agro-chemicals & Frequency & Percentage \\
\hline Fertilizer & 40 & 42.10 \\
Herbicides & 35 & 36.80 \\
Pesticides & 15 & 15.80 \\
Fungicides & 5 & 5.30 \\
Total & $\mathbf{9 5}$ & $\mathbf{1 0 0 . 0 0}$ \\
\hline
\end{tabular}

Source: Field Survey, 2012.

\section{Whether Agro-Chemicals are Harmful or Not}

Table 4 shows the distribution of respondents according to whether agro-chemicals are harmful or not. Majority of the respondents $(83.2 \%)$ responded that agro chemicals are harmful against and 16.8\% pointed out that agro-chemicals are not harmful. WHO (1986) estimated that about 20,000 people have died due to agrochemicals poisoning.

Table 4: Distribution of Respondents According to Whether Agro-Chemicals are Harmful or Not

\begin{tabular}{lll}
\hline Response & Frequency & Percentage \\
\hline Yes & 79 & 83.20 \\
No & 16 & 16.80 \\
Total & $\mathbf{9 5}$ & $\mathbf{1 0 0 . 0 0}$ \\
\hline
\end{tabular}

Source: Field Survey, 2012.

\section{Effects of Agro-chemicals on farm Income}

Table 5 shows that majority $51.58 \%$ of the respondents maintained that agro-chemicals did not affect their farm income, $48.42 \%$ pointed out that Agro-chemicals affects their farm income. According to Andrew 
(2008) the use of agro-chemicals accounts to sustainable yield (increase income). Most often the impact of these agro-chemicals are not felt or seen either due to wrong application or farmers bought the adulterated commodity in the open market.

Table 5: Distribution of Respondents According to the Effects of Agro-chemicals on farm income

\begin{tabular}{lll}
\hline Response & Frequency & Percentage \\
\hline Yes & 46 & 48.42 \\
No & 49 & 51.58 \\
Total & $\mathbf{9 5}$ & $\mathbf{1 0 0 . 0 0}$ \\
\hline
\end{tabular}

Source: Field Survey, 2012.

\section{Constraints to Agro-Chemicals Utilization}

The result of this study reveals that the major constraint to adoption of agro-chemicals is inadequate fund. Majority of the farmers are poor. They usually own a few number of animals whose droppings may not be adequate for their farms. On the other hand, some of the farmers pointed out that it is difficult to apply agrochemicals and they do not have the skill and equipment to use on their farms. Agro-chemicals application requires safety measures like hand globes, and protective clothing to avoid contact with body, this discourages farmers from applying agro-chemical on their farms. Most agro-chemicals possess offensive odour which may affect adoption, by and large some farmers maintained that they are allergic and hence do not like the odour and cannot use it on their farms.

Table 6: Some constraints to the use of agro-Chemicals

\begin{tabular}{llll}
\hline Constraints & Rank & Respondents & Percentage \\
\hline Lack of fund & 1 & 82 & 86.30 \\
Difficult to use & 2 & 7 & 7.40 \\
Difficult to learn & 3 & 6 & 6.30 \\
Total & & $\mathbf{9 5}$ & $\mathbf{1 0 0 . 0 0}$ \\
\hline
\end{tabular}

Source: Field Survey, 2012

Income (N) of Respondents

The result of this study (Table 7) shows that $18.95 \%$ of the respondents had an income of N200, 000N250, 000 and above due to utilization of agro-chemicals on their farms. Southgate (2006) posited that from the mid1960s through 1980s, the green revolution enabled millions of people in Asia and Latin America to escape famine and poverty, by increasing agricultural productivity through the use of modern agricultural techniques. In contrast, majority of African countries did not adopt those technologies and agricultural yields in most of these countries stagnated and declined in the same period. He concluded by stating that "today, millions of Africans suffered from malnutrition and continued to leave lives of penury engaged in toil subsistence agriculture". This is not a true reflection of what was obtainable in the study area.

Table 7: Distribution of Respondents According to Income (N)

\begin{tabular}{lcc}
\hline Income Group (Annually) (\#) & Frequency & Percentage \\
\hline$<50,000.00$ & 15 & 15.79 \\
$50,000.00-100,000.00$ & 14 & 14.74 \\
$100,000.00-150,000.00$ & 16 & 16.84 \\
$150,000.00-200,000.00$ & 17 & 17.89 \\
$200,000.00-250,000.000$ & 18 & 18.95 \\
$250,000.00-300.000 .00$ & 11 & 11.58 \\
3000.000 .00 and Above & 4 & 4.21 \\
Total & $\mathbf{9 5}$ & $\mathbf{1 0 0 . 0 0}$ \\
\hline
\end{tabular}

Source: Field Survey, 2012.

\subsection{Linear Equation of Simple Regression.}

The result of linear equation presented in (Table 8) shows a coefficient of multiple determinations $\left(\mathrm{R}^{2}\right)$ value of 0.036 which indicates that $3.6 \%$ of the variation in output was accounted for by the variation in explanatory variable used in the model. The remaining $96.4 \%$ may be attributed to error.

The coefficient of herbicide $\left(\mathrm{X}_{1}\right)$ was positive and significant $(\mathrm{P}<0.01)$ this agreed with findings of Shehu (2007). The positive coefficient suggests that a percentage increase in the variable would result to increased output level. This is in conformity with the apriori expectation. 
Assessment Of Agro-Chemicals Utilization By Small-Scale Farmers In Guyuk, Adamawa State,

Table 8: linear equation of simple regression

\begin{tabular}{llll}
\hline Variables & Coefficient & Standard error & F - value \\
\hline Herbicides $X_{1}$ & 0.514 & 0.277 & $1.853^{*}$ \\
Constant & 7558.801 & 1583.817 & $4773^{* * *}$ \\
$\mathrm{R}^{2}$ & 0.036 & & \\
$\mathbf{F}$ & $\mathbf{3 . 4 3 4}$ & & \\
\hline
\end{tabular}

Source: Computer Printout of the regression

Note $*=$ Significant at 0.01

$* * *=$ Significant at 0.1

Decision On level of Agro-chemical utilization by Age, Gender, Level of Education and Income

Table 9 shows $\mathrm{X}^{2}$ at $10 \mathrm{DF}$ at 0.05 level of significance $=1.812$. The calculated $\mathrm{X}^{2}$ value $(16.094)$, is greater than the critical (Table) value, this indicates that there was a significant association between Agrochemicals utilization and age.

$\mathrm{X}^{2}$ result in Table 10 at $2 \mathrm{DF}(0.05)$ level of significance $=1.697$. The calculated $\mathrm{X}^{2}$ value $(0.122)$ is less than critical (Table) value; this shows that there was no significant association between Agro-chemical utilization and Gender.

Table $11 \mathrm{X}^{2}$ at $6 \mathrm{DF}(0.05)$ level of significance $=1.943$. The calculated $\mathrm{X}^{2}$ value $(27.479)$ is greater than the critical (Table) value, indicating that there was a significant association between Ago-chemicals utilization and level of education.

Table $12 \mathrm{X}^{2}$ at $12 \mathrm{DF}(0.05)$ level of significance $=1.782$. The calculated $\mathrm{X}^{2}$ value $(22.288)$ is greater than the critical (table) value, these revealed that there was significant association between Agro-chemicals utilization and income.

Table 9: Level of Utilization of Agro-Chemicals as Influenced by Age

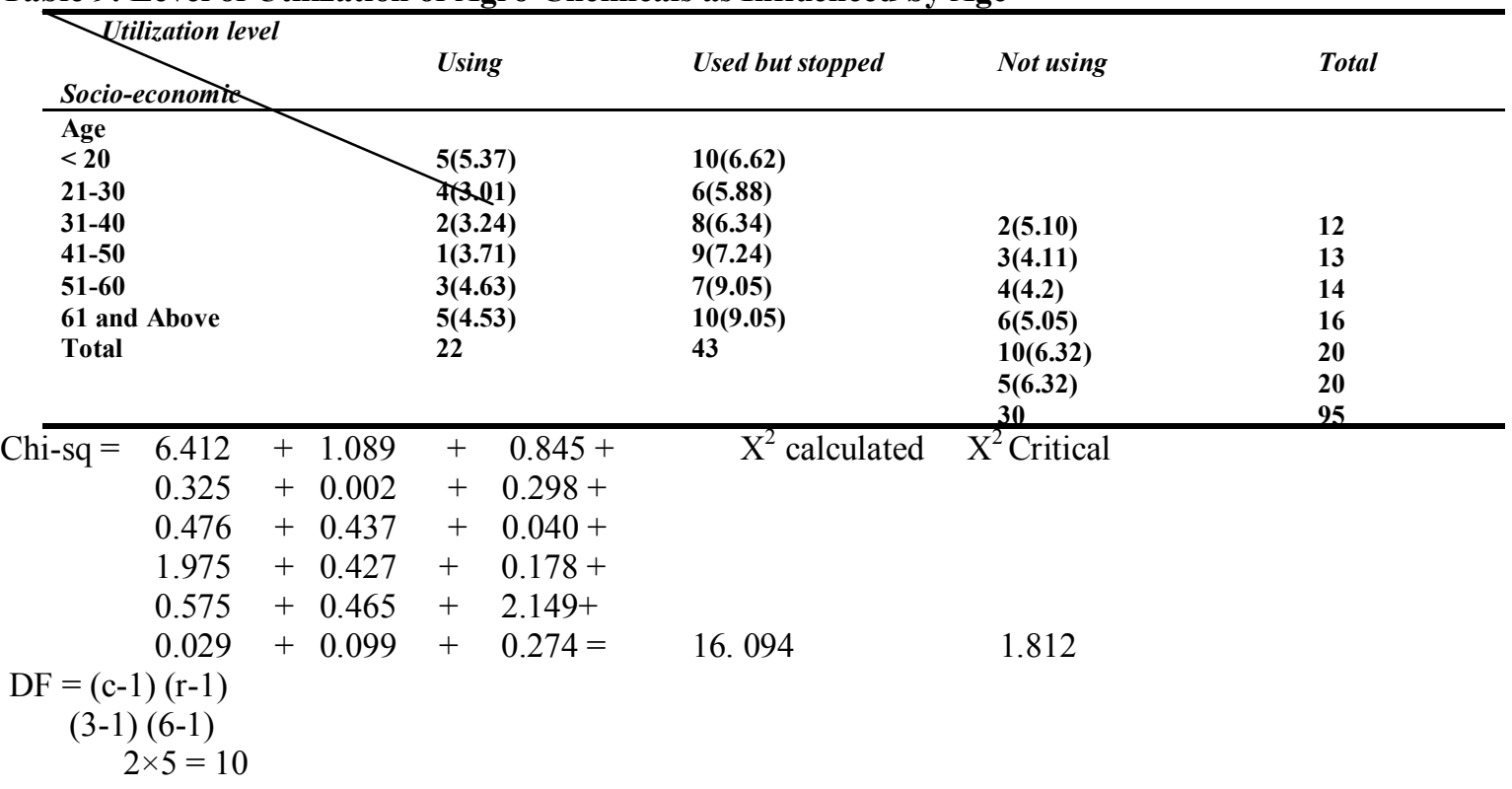

Table 10: Level of Utilization of Agro- Chemicals as Influenced by Gender

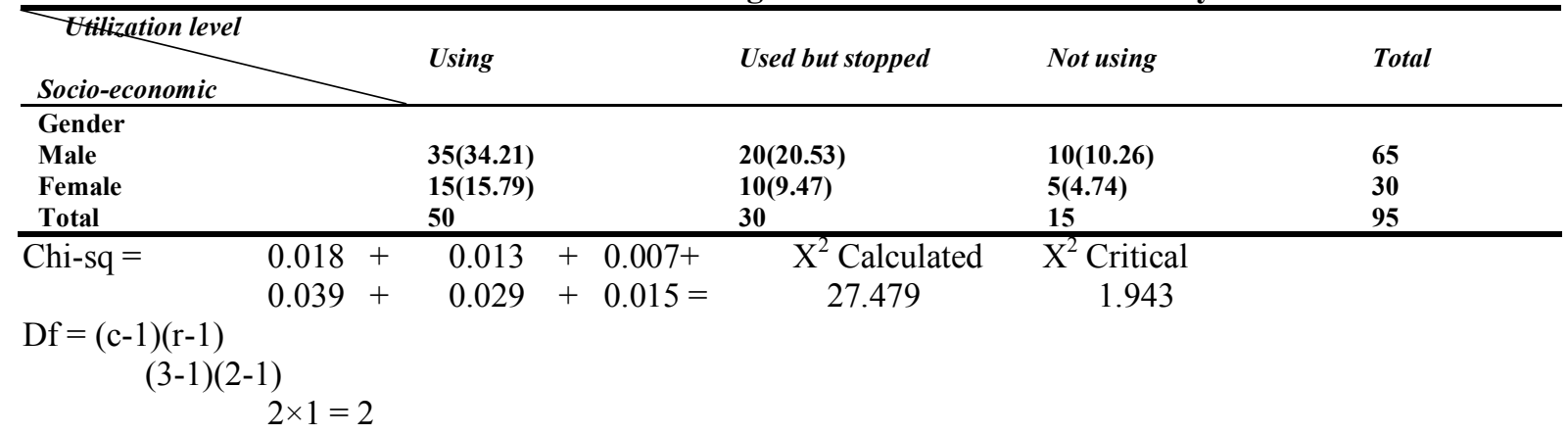


Assessment Of Agro-Chemicals Utilization By Small-Scale Farmers In Guyuk, Adamawa State,

Table 11: Level of Utilization of Agro-Chemicals as Influenced by Level of Education

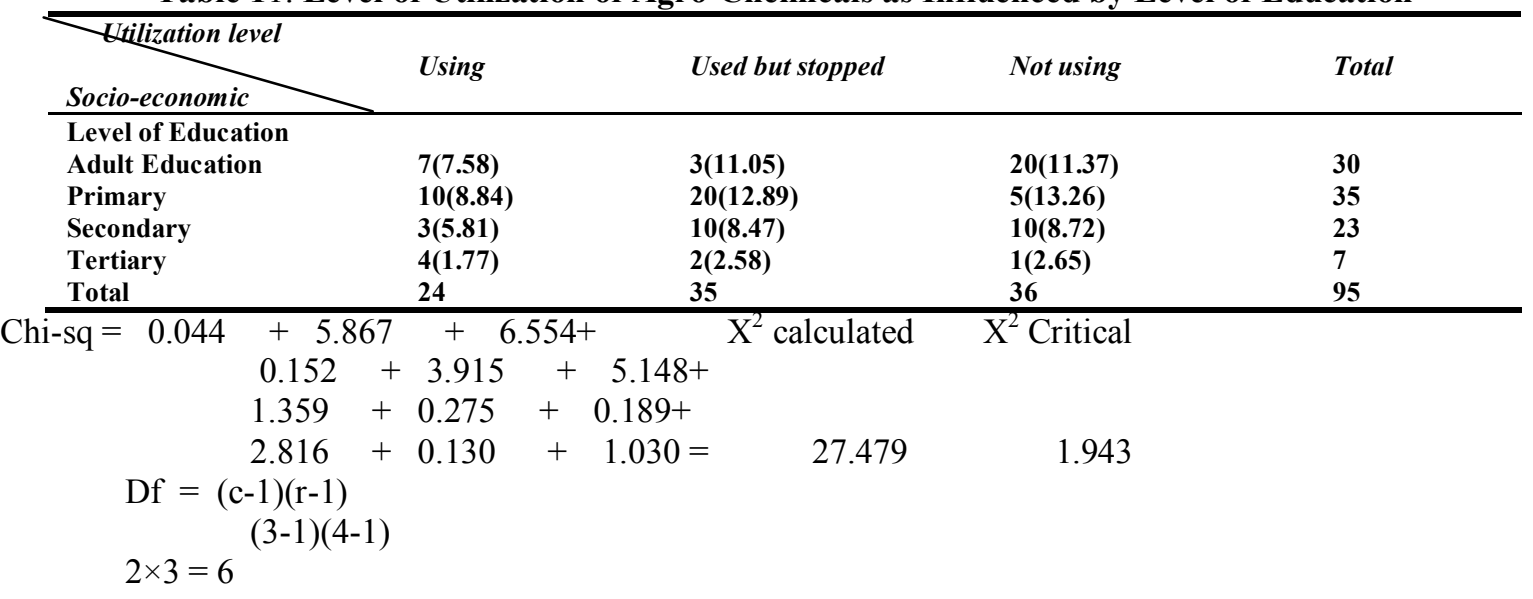

Table: 12 Level of Utilization of Agro-Chemicals as Influenced by Income (A)

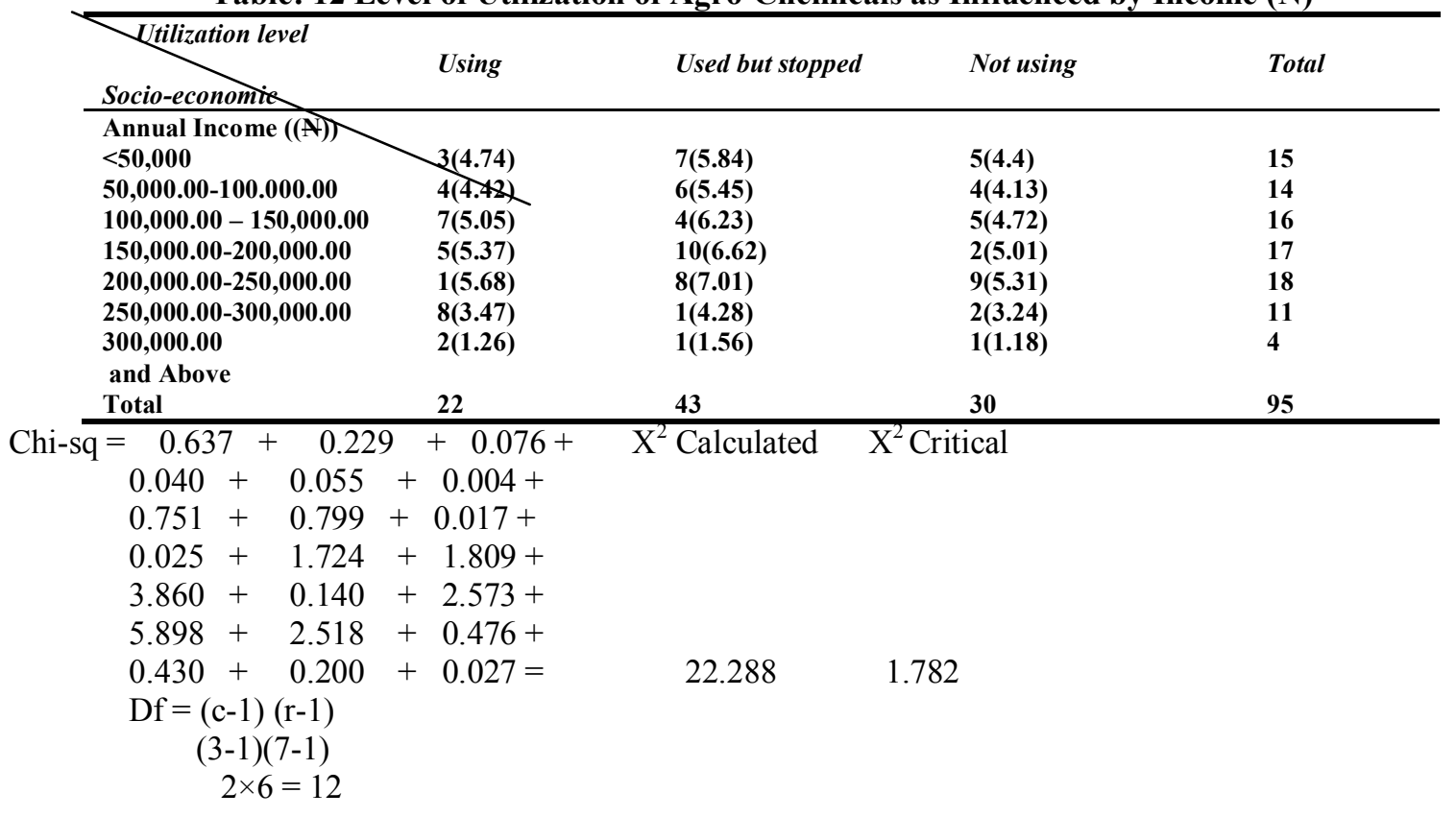

\section{Conclusion}

From the result of this study, majority of the respondents $(84.2 \%)$ adopt the use of agro-chemicals in the study area as a source of increasing soil fertility and productivity. Conclusively, the $\mathrm{X}^{2}$ at $10 \mathrm{DF}, 6 \mathrm{DF}$ and $12 \mathrm{DF}$ at 0.05 level of significance $=1.812,1.943$ and 1.782 . The calculated $\mathrm{X}^{2}$ values of $16.094,22.479$ and 22.288 are greater than critical (table) values, this revealed that there was significance association between agro-chemicals utilization and some selected socio-economic variables: Age, Level of education and income while the $\mathrm{X}^{2}$ at $2 \mathrm{DF}$ at 0.05 level of significance $=1.697$. The calculated value $(0.122)$ is less than the critical (Table) value, so the result indicates that there was no significant association between Agro-chemicals utilization and Gender.

\section{References}

[1]. Adamawa State Diary (1999). Ministry of Information, Yola, Adamawa, Nigeria

[2]. Agwu, L.and Anyanwu, A. C. (1996). Factors Associated With the Adoption of Farm Practices in Western Nigeria. Resources Bulleting No 1 Faculty of Agriculture. Oxford University Press (19) Pp.53

[3]. Alex, G. (2007). Organic abundance report: fatally flawed-commentary. Renewable Agriculture and food systems a (Cambridge: University press) 22(4): Pp321-323.

[4]. Albert, H. (1989). Why organic manure are better than chemical fertilizer. Journal of Agriculture. Oxford University Press (19)1 pp. 53-59.

[5]. Andrew, W. (2007). http://disaster.itas.uft.edu/agrochemical security. htm agrow (538):5 retrieved $5^{\text {th }}$ Dec. 2011.

[6]. Andrew, W. (2008). http:top six all head in (2008) agrow (539: 3. March 14, 2008. Retrieved $18^{\text {th }}$ Dec. 2011

[7]. Ajayi,A.O (2006). A Study of occupational safety practices among rural Farmers in Ile-Ife area of Ogun State, Nigeria. An emphasis on relevant training needs Journal of Agricultural and Biological Sciences 2(5): 227-235 
[8]. Bzugu, P.M, and Gwary, M.M. (2005). Effective Communication by Extensive Agent as a Determinant of Farmers' adoption of recommended Agricultural Technologies in Adamawa state Nigeria. Journal of Sustainable Development in Agriculture and Environment. (1):55-59.

[9]. FAO/WHO (Food and Agricultural Organization of the United Nation and World Health organization 1988). Guidelines for predicting the dietary intake of Pesticide residues. Bulletin of the World health organization. 66, 429-429-434.

[10]. Fleisher, G. (2006). Agricultural chemical- how much input is required, how much is too much. Agricultural and rural Sociology development vol. 1. Pp51-53.

[11]. FRN, (2007). The Federal Republic of Nigeria Official Gazette National Population Census. Pp 6.

[12]. Gombe, S. and Ogada, T.A (1988). Health of Men on long term exposure To Pyrethrins. East African Medical Journal, 65,734-742

[13]. Ifah, S.S (1986). Expectancy theory and career decision making. A decision-theoretic and policy capturing approach. Unpublished $\mathrm{Ph} . \mathrm{D}$ Thesis University of Wales Institute of Science and Technology

[14]. Katikpo, G. (2003). The Assessment of Adoption Rate of Improved Production Technology among Farmers in Kokona LGA of Nasarawa State. An Unpublished B. Tech. Project. Agricultural Economics and Extension Progamme. Abubakar Tafawa Balewa University, Bauchi.

[15]. Maisamari, J.Y (2001). Way of revamping agro-based industries in Nigeria. Retrieved from http//www.cenbankorg/out/publication/occational paper/od/2001/ow2e01.pdf,20 $0^{\text {th }}$ April, 2010.

[16]. Misanin, J.R and Hinderliter C.F (1991). Fundamental of statistics for psychology students New York: Harper Collins Publishers inc.

[17]. NEH, (2000). The role of small-scale industries in Nigeria Economy. Retrieved from http;//www/interscience, willey.com/journal/118987927/abstract 19 march2010

[18]. Peres, F. Moriera, C.J, Rodrigues, m. and Claudio, L. (2006). Risk perception and communication regarding pesticide used in rural work: a case study of Rio de Janeiro state, Brazil, International journal of occupational and environmental health 12:400-407.

[19]. Seattle, P.I (2008). The Lowdown On Top Soil: It Is Disappearing. Small And Medium Enterprise And Finding In Nigeria

[20]. SMSEFN. (2003), Nigeria economy depends on the recognition of small and medium enterprises. Retrieved from: http:ww/interscience:wettry:com/harnnal/18987927/ abstract $28^{\text {th }}$ may, 2010

[21]. Southgate, D and Graham D (2006). Growing Green: The Challenge of Sustainable Agricultural Development in Sub-Saharan Africa. The Sustainable Development Network August, 2006.

[22]. Taylor, T. A. (2003), Manual of Small Farming in West Africa for Improved Production and Better Family Living. Revised Edition. Loud Publisher. Pp.3

\section{Acknowledgements}

The authors would like appreciate all farmers for their responses and information provided for this study. Thanks also to the staff of Adamawa Agricultural Development Programme, Guyuk local government authority, Adamawa State, Nigeria. 